\title{
Replacement Process of Carbonate Apatite by Alveolar Bone in a Rat Extraction Socket
}

\author{
Xiaoxu Zhang ${ }^{1,2}{ }^{(0)}$, Ikiru Atsuta ${ }^{2, *}{ }^{\oplus}$, Ikue Narimatsu ${ }^{1}$, Nobuyuki Ueda ${ }^{1}\left(\mathbb{D}\right.$, Ryosuke Takahashi ${ }^{1}$, Yuki Egashira ${ }^{1}$,

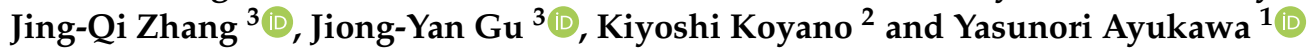

1 Section of Implant and Rehabilitative Dentistry, Division of Oral Rehabilitation, Faculty of Dental Science, Kyushu University, Fukuoka 812-8582, Japan; xiaoxu3535@dent.kyushu-u.ac.jp (X.Z.); narimatu.i@dent.kyushu-u.ac.jp (I.N.); nobuyuki@dent.kyushu-u.ac.jp (N.U.); tkhsrsk@dent.kyushu-u.ac.jp (R.T.); egashirayuki@dent.kyushu-u.ac.jp (Y.E.); ayukawa@dent.kyushu-u.ac.jp (Y.A.)

2 Division of Advanced Dental Devices and Therapeutics, Faculty of Dental Science, Kyushu University, Fukuoka 812-8582, Japan; koyano@dent.kyushu-u.ac.jp

3 Department of Molecular Cell Biology and Oral Anatomy, Faculty of Dental Science, Kyushu University, Fukuoka 812-8582, Japan; zhangjq@dent.kyushu-u.ac.jp (J.-Q.Z.); gujy@dent.kyushu-u.ac.jp (J.-Y.G.)

* Correspondence: atyuta@dent.kyushu-u.ac.jp; Tel.: +81-92-642-6441; Fax: +81-92-642-6380

\section{check for} updates

Citation: Zhang, X.; Atsuta, I.; Narimatsu, I.; Ueda, N.; Takahashi, R.; Egashira, Y.; Zhang, J.-Q.; Gu, J.-Y.; Koyano, K.; Ayukawa, Y.

Replacement Process of Carbonate Apatite by Alveolar Bone in a Rat Extraction Socket. Materials 2021, 14, 4457. https://doi.org/10.3390/ ma14164457

Academic Editor: Roman Perez Antoñanzas

Received: 12 July 2021

Accepted: 6 August 2021

Published: 9 August 2021

Publisher's Note: MDPI stays neutral with regard to jurisdictional claims in published maps and institutional affiliations.

Copyright: (c) 2021 by the authors. Licensee MDPI, Basel, Switzerland. This article is an open access article distributed under the terms and conditions of the Creative Commons Attribution (CC BY) license (https:// creativecommons.org/licenses/by/ $4.0 /)$.

\begin{abstract}
The objective of this study was to investigate a bone graft substitute containing carbonate apatite $\left(\mathrm{CO}_{3} \mathrm{Ap}\right)$ to analyze bone replacement and the state of bone formation in vitro and in vivo compared with autogenous bone $(\mathrm{AB})$ or control. An osteoclast precursor cell line was cultured with $\mathrm{AB}$ or $\mathrm{CO}_{3} \mathrm{Ap}$, and morphological analysis using scanning electron microscopy and a tartrateresistant acid phosphatase activity assay were performed. The right maxillary first and second molars of Wistar rats were extracted and compensated by $\mathrm{AB}$ or $\mathrm{CO}_{3} \mathrm{Ap}$ granules. Following implantation, the bone formation state was evaluated after $3,5,7,14$, and 28 days of surgery by micro-computed tomography and immunohistostaining. The osteoclast-like cell morphology was typical with many cell protrusions in the $\mathrm{AB}$ and $\mathrm{CO}_{3} \mathrm{Ap}$ groups. Additionally, the number of osteoclast-like cells formed in the culture increased in each group; however, there was no significant difference between the $\mathrm{AB}$ and $\mathrm{CO}_{3} \mathrm{Ap}$ groups. Five days after tooth extraction, osteoclasts were observed near $\mathrm{CO}_{3} \mathrm{Ap}$. The bone thickness in the $\mathrm{CO}_{3} \mathrm{Ap}$ group was significantly increased than that in the control group and the bone formation in the $\mathrm{CO}_{3} \mathrm{Ap}$ group increased by the same level as that in the AB group. $\mathrm{CO}_{3} \mathrm{Ap}$ is gradually absorbed by osteoclasts in the extraction socket and is easily replaced by alveolar bone. The process of bone replacement by osteoclasts is similar to that of autologous bone. By observing the process of bone replacement in more detail, it may be possible to gain a better understanding of the bone formation and control the amount of bone after surgery.
\end{abstract}

Keywords: carbonate apatite; bone substitute; autogenous bone; osteoclast

\section{Introduction}

Alveolar bone resorption is an important issue in all types of defective prosthesis treatment, including dental implants, and osteogenesis is necessary to repair the bone. There are various bone grafting materials available for bone augmentation; however, clinical application requires an understanding of their various advantages and disadvantages. Of these, autogenous bone is the first choice for bone augmentation materials [1].

Autogenous bone is the gold standard bone replacement material because of its superior osteoconductive and osteoinductive properties [1,2]. Osteogenesis requires a bone-replacement material as a scaffold for healing, in which the scaffold does not damage or introduce antigenicity to the surrounding tissue, promotes vascularization and osteogenesis, and can easily be replaced with new bone after filling. Only fresh autogenous bone can successfully and effectively replace bone. Intuitively, one can think of the null hypothesis as stating that any artificial bones are not as good as autogenous bones. 
However, autogenous bone grafting has two major disadvantages. First, in elderly patients and patients with large bone defects, the collection of autogenous bone is a serious surgery and the amount of bone collected is limited [2]. Second, it is difficult to control the amount of bone after autogenous bone grafting [3] because even if similar or the same quality bone is added to the site where bone resorption originally occurred, it can easily be resorbed again by remodeling. Contrary to autogenous bone, artificial bone is not similarly absorbed by the body to enable space for osteoblast activity until sufficient bone is repaired [4].

A typical material for artificial bone is hydroxyapatite (HA), which is a tooth enamel component. However, because HA remains at the site without being replaced for a long period of time, there is a risk of infection [5,6]. It is important to have a composition similar to that of bone for biocompatibility; however, when considering "space making" for bone formation, it is also necessary to have a low absorption rate. Therefore, an artificial material with a composition similar to that of autogenous bone, such as a bone substitute containing carbonate apatite $\left(\mathrm{CO}_{3} \mathrm{Ap}\right)$ that is an inorganic component of bone, has gained clinical attention $[7,8]$. Such composites have been clinically applied for excellent results; however, it is difficult to predict the control of absorption clinically, which is critical to bone regeneration [8]. We previously focused on using osteoclast activity as an evaluation method of bone remodeling. Osteoclasts also initiate bone formation [9].

In this study, we investigate the process in which $\mathrm{CO}_{3} \mathrm{Ap}$ in an extraction socket is absorbed in vivo and replaced with bone. We considered the mechanism in which $\mathrm{CO}_{3} \mathrm{Ap}$ used for bone augmentation in clinical practice is replaced with bone.

\section{Materials and Methods}

\subsection{Materials}

Autogenous bone $(\mathrm{AB})$ and $\mathrm{CO}_{3} \mathrm{Ap}$ were used in the experiment as bone filling materials. $\mathrm{AB}$ was collected from the femur and tibia of three male 6-week-old Wistar rats with a bone scraper (Osteogenics, Lubbock, TX, USA). Cytrans ${ }^{\circledR}$ (GC, Tokyo, Japan) is a pure $\mathrm{CO}_{3} \mathrm{Ap}$ dense granule fabricated in an aqueous solution through a dissolution precipitation reaction using $\mathrm{Ca}(\mathrm{OH})_{2}$ granules as precursors [10-13]. The $\mathrm{CO}_{3} \mathrm{Ap}$ granules were $300-600 \mu \mathrm{m}$ in diameter.

\subsection{Osteoclast Precursor Cell Line RAW-D Cells Culture}

Osteoclast-like cells were differentiated from murine osteoclast precursor cell line RAW-D cells (a subclone of RAW264 cells) as previously described [14-16]. Briefly, RAW-D cells were cultured in $\alpha$-modified Eagle's medium ( $\alpha$-MEM, Wako, Osaka, Japan), $10 \%$ fetal bovine serum (FBS, Thermo Fisher Scientific, Waltham, MA, USA) in the presence of recombinant human soluble receptor activator NF-kB ligand (RANKL) $(50 \mathrm{ng} / \mathrm{mL}$, Oriental Yeast, Tokyo, Japan) for 4 days (Figure 1A).

\subsection{Tartrate-Resistant Acid Phosphatase (TRAP) Activity Assay}

Osteoclasts were examined using a commercial TRAP staining kit (Sigma-Aldrich, St. Louis, MO, USA) for the osteoclast marker TRAP activity [17]. Following incubation for 4 days, the cells were fixed in 10\% formalin (Wako, Osaka, Japan), permeabilized using ethanol/acetone (Wako, Osaka, Japan), and observed with light microscopy (BZ-X800, Keyence, Osaka, Japan). Fifteen samples (five per groups) were analyzed in the TRAP activity assay.

\subsection{Number of TRAP-Positive Cells}

RAW-D cells $\left(6.8 \times 10^{3} / \mathrm{mL}\right)$ were seeded on experimental and control groups. AB and $\mathrm{CO}_{3} \mathrm{Ap}$ were ground to a particle size of $200 \mu \mathrm{m}$ or less and added at a concentration of $50 \mathrm{ng} / \mathrm{mL}$ RANKL for 4 days. The number of multinucleated TRAP-positive cells was counted, converted per well, and the average was compared with the control. The samples were observed with light microscopy (BZ-X800, Keyence, Osaka, Japan). The number of 
TRAP-positive cells was calculated using cell count of BZ-X800 Analyzer software version 1.1.1.8 (Keyence, Osaka, Japan).

\subsection{Scanning Electron Microscopy}

Bovine dentin pieces $\left(8.0 \mathrm{~mm} \times 4 \mathrm{~mm}, \mathrm{GC}\right.$, Tokyo, Japan) and $\mathrm{CO}_{3} \mathrm{Ap}$ plates $(\varphi 9.0 \mathrm{~mm} \times 1 \mathrm{~mm}$ provided by GC, Tokyo, Japan) were immersed in $\alpha$-MEM containing $10 \%$ FBS in the presence of $50 \mathrm{ng} / \mathrm{mL}$ RANKL at $4{ }^{\circ} \mathrm{C}$ for 4 days. RAW-D cells $\left(6.8 \times 10^{3} / \mathrm{mL}\right)$ were seeded on the materials. RAW-D cells in culture dish (Nalge Nunc, Rochester, NY, USA) were used as the control. The RAW-D cell morphology on the control culture dish or $\mathrm{CO}_{3} \mathrm{Ap}$ plates, and bovine dentin pieces was evaluated by scanning electron microscopy (SEM) (S-3400N, Hitachi, Tokyo, Japan) at $15 \mathrm{kV}$. All samples were fixed with $2.5 \%$ glutaraldehyde for $30 \mathrm{~min}$. The fixed cells were rinsed in phosphate buffer saline (PBS), dehydrated in a graded ethanol series, and lyophilized. Specimens were coated with $\mathrm{Au} / \mathrm{Pd}$ alloy and evaluated microscopically [18].

\subsection{Animals}

Fifteen male Wistar rats (6-week-old, body weight 160-180 g, five per groups) were used in the in vivo experiments.

All experiments were performed in accordance with the ARRIVE Guidelines for reporting animal research [19]. All procedures involving experimental animals were approved by the Institutional Animal Care and Use Committee of Kyushu University (Approval Number: A25-240-0).

\subsection{Tooth Extraction Socket Model}

The experimental schedule is shown in Figure 2A. The right maxillary first (M1) and second molars (M2) were extracted under a combination anesthetic $(0.3 \mathrm{mg} / \mathrm{kg}$ of medetomidine, $4.0 \mathrm{mg} / \mathrm{kg}$ of midazolam, and $5.0 \mathrm{mg} / \mathrm{kg}$ of butorphanol) [20]. After extraction, the alveoli were filled with $\mathrm{AB}, \mathrm{CO}_{3} \mathrm{Ap}$, or without filling and the animals were randomly selected into three groups (control, $\mathrm{AB}$, and $\mathrm{CO}_{3} \mathrm{Ap}$ ).

\subsection{Micro-Computed Tomography}

Each day after the rats were sacrificed, their maxillae were corrected, and fixed in $4 \%$ paraformaldehyde (Merck, Darmstadt, Germany) for $24 \mathrm{~h}$. Micro-computed tomography (micro-CT) imaging was performed by micro-CT (SkyScan 1076, Bruker, Kontich, Belgium) using X-ray energy with a tube current of $201 \mu \mathrm{A}$ and voltage of $49 \mathrm{kV}$. Threedimensional analysis software version 1.18.8 (CTAn, Bruker, Kontich, Belgium) was used for analysis [21].

\subsection{Bone Histomorphometry}

An image of the frontal fracture was captured using micro-CT, and the vertical length to the base of the extraction socket was measured as the bone thickness. The anteroposterior position was located by the central part of the second molar (maximum crown diameter) on the opposite side.

\subsection{Tissue Preparation and Histological Staining}

Tissues were prepared as described in a previous study [18,22]. Briefly, at each time point, the rats were sacrificed and their maxillae were isolated and immersed in $4 \%$ paraformaldehyde for $24 \mathrm{~h}$, followed by decalcified in Kalkitox ${ }^{\mathrm{TM}}$ solution (Wako, Osaka, Japan) exposure at $4{ }^{\circ} \mathrm{C}$ for $18 \mathrm{~h}$. The frozen samples were immersed in $20 \%$ sucrose overnight at $4{ }^{\circ} \mathrm{C}$. The samples were next embedded in Optimal Cutting Temperature compound (Sakura Finetek, Tokyo, Japan) at $4{ }^{\circ} \mathrm{C}$ for $2 \mathrm{~h}$ and then cut into $10-\mu \mathrm{m}$-thick sagittal sections using a cryostat (CM1860, Leica Microsystems, Wetzlar, Germany) at $-20{ }^{\circ} \mathrm{C}$. Sections were stained with hematoxylin and eosin (HE) for recognizing tissue 
types and the morphologic changes or Azan stains for the collagen fibers (Figure 3A,B) [23]. In addition, some sections were subject to TRAP staining for the osteoclasts [17].

\subsection{Immunofluorescence Staining Procedure}

Sections prepared from the $\mathrm{CO}_{3}$ Ap group 5 days after tooth extraction were immunostained. After unreacted aldehyde groups were quenched with $10 \mathrm{mM}$ glycine, sections were blocked in 10\% chick albumin for $60 \mathrm{~min}$ at room temperature, followed by further blocking in $10 \%$ normal goat serum for $2 \mathrm{~h}$ at room temperature. Sections were then incubated with a mixture of Acti-stain ${ }^{\mathrm{TM}} 488$ Fluorescent Phalloidin (1:40 dilution, Cytoskeleton, Denver, CO, USA) to detect F-actin filaments, and anti-cathepsin K antibody (1:50 dilution, Santa Cruz Biotechnology, Santa Cruz, CA, USA) to detect osteoclast or control IgG at room temperature for $4 \mathrm{~h}$ in a moisture chamber. The sections were washed with PBS and incubated with goat anti-mouse $\operatorname{IgG}(\mathrm{H}+\mathrm{L})$ antibody conjugated with Alexa Fluor 568 (1:300 dilution, Invitrogen, Waltham, MA, USA) for $30 \mathrm{~min}$ [24,25]. Nuclei were stained with 4',6-diamidino-2-phenylindole (DAPI) (1:50 dilution, Sigma-Aldrich, St. Louis, MO, USA). The samples were observed with Apotome 2 microscopy (Zeiss, Oberkochen, Germany).

\subsection{Statistical Analysis}

Our experiment used 5 samples and all data were expressed as means \pm standard deviation (SD) from at least three independent experiments. One-way analysis of variance (ANOVA) with Tukey's test was performed. Values of $p<0.05$ were considered significant.

\section{Results}

\subsection{Number of Osteoclasts}

The in vitro culture experiment was performed according to the time schedule shown in Figure 1A. As shown in Figure 1B, the number of TRAP-positive cells increased significantly on $\mathrm{AB}$ and $\mathrm{CO}_{3} \mathrm{Ap}$ compared with the control. However, there were no significant differences between $\mathrm{AB}$ and $\mathrm{CO}_{3} \mathrm{Ap}$ groups.

(A)

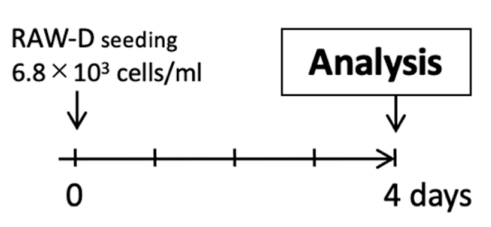

(C)

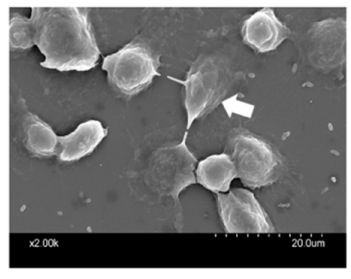

Control
(B)

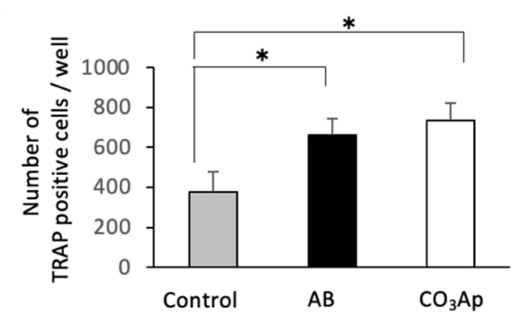

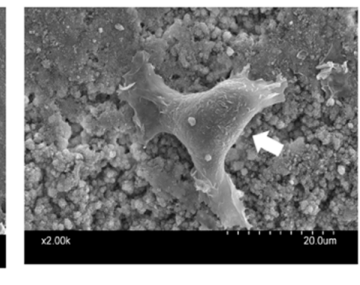

$\mathrm{CO}_{3} \mathrm{Ap}$

Figure 1. Evaluation of osteoclast activity in an in vitro study. (A) Experimental protocol of the in vitro study. (B) The number of TRAP positive cells (white arrows) $\left(n=5,{ }^{*} p<0.05\right)$. (C) The shape of the osteoclast-like cells (control: culture dish, $\mathrm{AB}$ : dentin piece, $\mathrm{CO}_{3} \mathrm{Ap}$ : Cytrans disc).

\subsection{Morphological Changes in the Osteoclasts}

As shown in the SEM image in Figure 1C, many oval osteoclast-like cells were observed in the control group, and stellate and extended osteoclast-like cells were observed in the $\mathrm{AB}$ and $\mathrm{CO}_{3} \mathrm{Ap}$ groups. In addition, cell protrusion tips adhered to the material surface. 


\subsection{Chronological Change of the Bone Amount}

Animal experiments were performed according to the time schedule shown in Figure 2A. The extraction socket was observed by a frontal cut using micro-CT (Figure 2C) with the central part of the second molar on the opposite side a measurement landmark (Figure 2B, red dotted line). Compared with the surrounding bone, $\mathrm{CO}_{3} \mathrm{Ap}$ shows a high $\mathrm{CT}$ value and appears as high density on the $\mathrm{CT}$ images (Figure 2D). Surfaces with $\mathrm{CO}_{3} \mathrm{Ap}$ in the extraction socket were observed until day 28 , and it was confirmed that the sites were replaced with new bone on day 14 . And the granule size was reduced day-by-day. The thickness of the bone was also evaluated using a micro-CT image (Figure 2E). Five days after tooth extraction, a significant increase in the thickness of the bone in $\mathrm{AB}$ and $\mathrm{CO}_{3} \mathrm{Ap}$ groups was observed compared with the control group. Twenty-eight days after tooth extraction, the thickness of the new bone significant increase was only observed in the $\mathrm{CO}_{3} \mathrm{Ap}$ group compared with the control group.

(A)

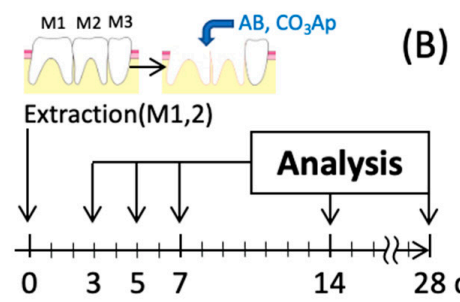

(B)

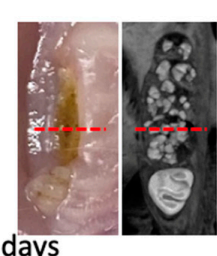

(C) Alveolar

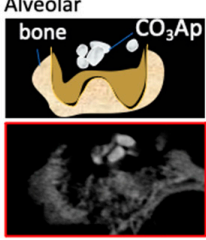

(D)

$3 d$

$5 d$

$7 d$

$14 d$

$28 d$

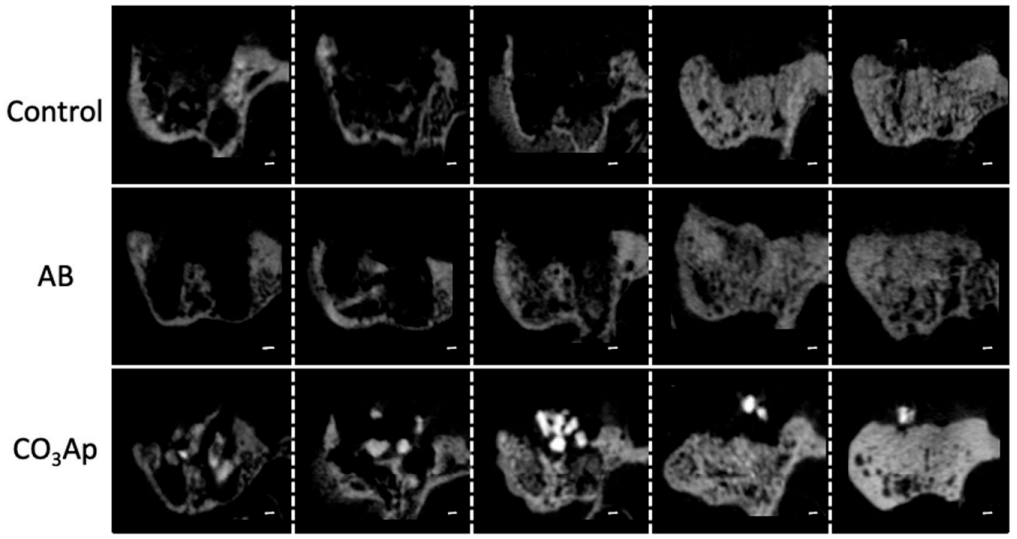

(E)

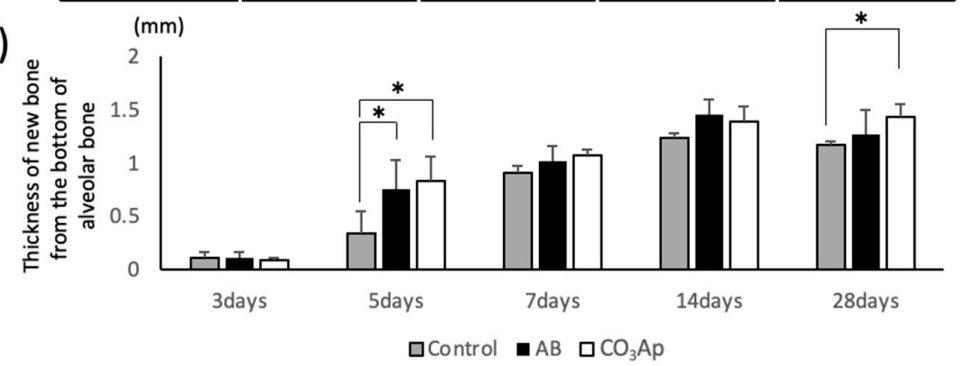

Figure 2. Evaluation of the chronological bone formation with micro-CT. (A) Schematic of the tooth extraction model. The right maxillary first (M1) and second molars (M2) were replaced by bone substitute. Experimental protocol of the in vitro study as described in the Materials and Methods section. (B) Landmark of the micro-CT image. The anteroposterior position at that time was located by the central part of the second molar (maximum crown diameter) on the opposite side. (C) Image of the frontal section at the observation site (schematic and CT image). (D) Evaluation of chronological changes in the extraction socket using micro-CT (control: extraction socket, AB: with autogenous bone, $\mathrm{CO}_{3} \mathrm{Ap}$ : with Cytrans). Bars $=200 \mu \mathrm{m}$. (E) Thickness of the new bone from the bottom of the alveolar bone $(n=5, * p<0.05)$. 


\subsection{Chronological Change of the Alveolar Bone Morphology after Tooth Extraction}

The extraction socket in each group was stained with $\mathrm{HE}$ and observed over time to understand the healing process (Figure 3A). Accumulation of inflammation-related cells, such as neutrophils, was not observed in all groups, and inflammatory findings, such as infectious granulation, were also not observed. Five days after tooth extraction, a rapid recovery of bone thickness was observed in the $\mathrm{AB}$ and $\mathrm{CO}_{3} \mathrm{Ap}$ groups. Seven days after the extraction, the bone thickness around the extraction socket of the $\mathrm{AB}$ and $\mathrm{CO}_{3} \mathrm{Ap}$ groups was flatter than the surrounding alveolar bone thickness (red dots line in Figure 3B). In addition, angiogenesis was observed around the $\mathrm{CO}_{3} \mathrm{Ap}$ granules (black arrowheads in Figure 3A).

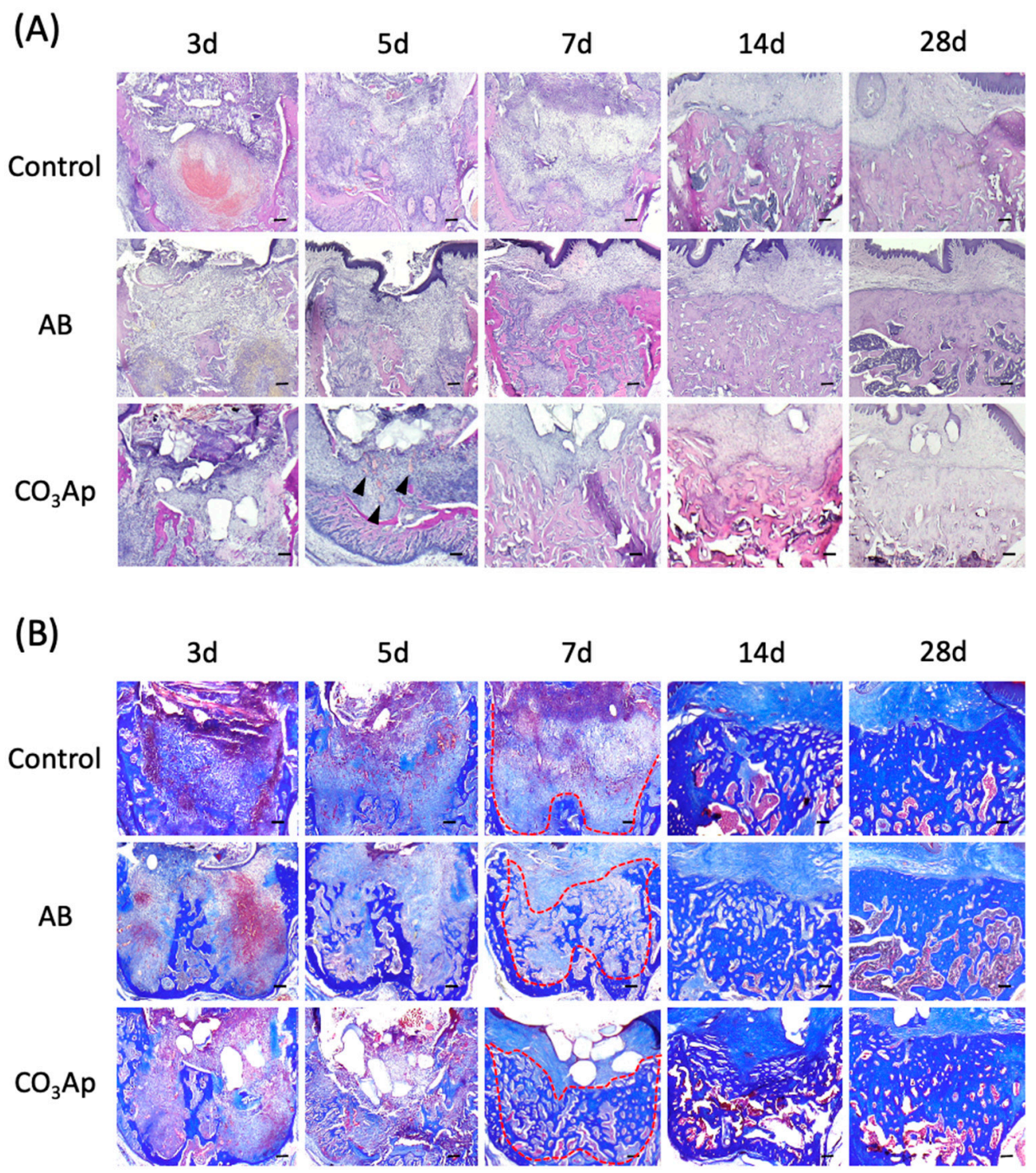

Figure 3. Chronological change of the alveolar bone morphology after tooth extraction. (A) Evaluation using HE staining. The black arrowheads indicate angiogenesis. Bars $=100 \mu \mathrm{m}$. (B) Azan staining shows collagen-rich new bone and the red dots line indicates border of the bone. Each slice shows the serial section from (A). Bars $=100 \mu \mathrm{m}$.

As shown in Figure 3B, Azan staining was performed using a serial section compared with the HE staining in Figure $3 \mathrm{~A}$. Immature bone formation was observed in the $\mathrm{AB}$ and $\mathrm{CO}_{3}$ Ap group 5 days after tooth extraction, and rapid bone formation was observed in the $\mathrm{AB}$ group and $\mathrm{CO}_{3} \mathrm{Ap}$ group 14 days later. Twenty-eight days after tooth extraction, densification of new bone was observed in the $\mathrm{AB}$ group and $\mathrm{CO}_{3} \mathrm{Ap}$ group. 


\subsection{Activity of Osteoclasts around $\mathrm{CO}_{3} A P$}

Five days after tooth extraction, TRAP staining revealed osteoclasts accumulating around $\mathrm{CO}_{3} \mathrm{Ap}$ (Figure 4A). Large cells with multiple nuclei were observed (black arrowheads in Figure 4A). Furthermore, cathepsin K, another marker of osteoclast, was used to stain serial sections, and positive cells were observed around $\mathrm{CO}_{3} \mathrm{Ap}$ (white arrowheads in Figure 4B).
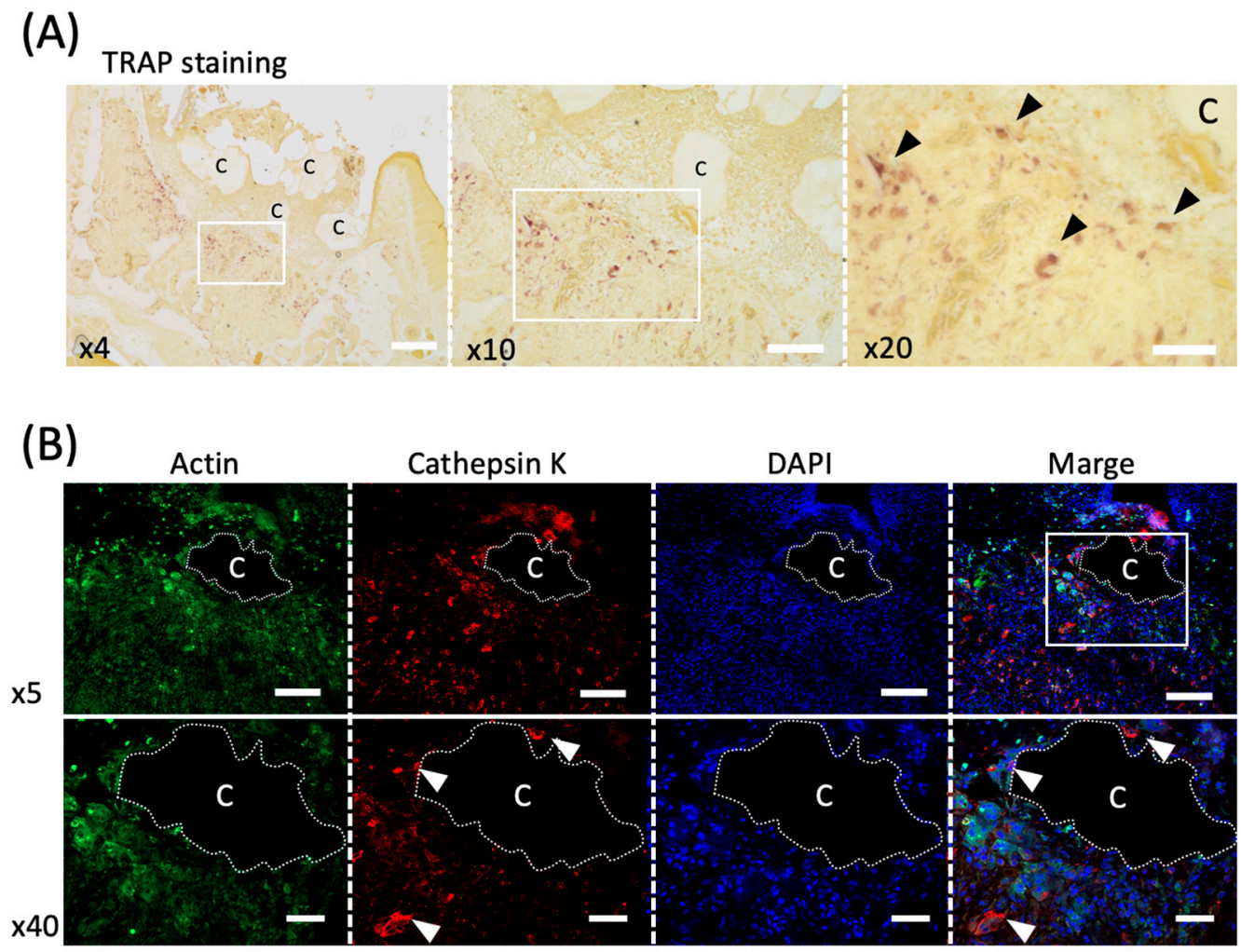

Figure 4. Evaluation of the osteoclast activity in an in vivo study. (A) TRAP staining of the healing socket 5 days after tooth extraction. The black arrowheads indicate osteoclasts. C; Cytrans. Bars $=300 \mu \mathrm{m}(\times 4), 200 \mu \mathrm{m}(\times 10), 100 \mu \mathrm{m}(\times 20)$. (B) Immunofluorescence staining of cathepsin $\mathrm{K}$ (red), F-actin (green) and DAPI (nuclei, blue) in upper panel $(\times 5)$ and lower panel $(\times 40)$. White arrowheads indicate multinucleated osteoclasts co-localized with cathepsin K and DAPI. C; Cytrans (white dots area). Bars $=500 \mu \mathrm{m}(\times 5), 100 \mu \mathrm{m}(\times 40)$.

\section{Discussion}

In this study, the process of $\mathrm{CO}_{3} \mathrm{Ap}$ replacement to bone was observed over time using a rat molar extraction socket model. The method for observing wound healing of the extraction socket has been widely used for evaluating bone formation [26]. Alternatively, there have been many previous studies evaluating bone formation using femur and calvaria models $[7,27]$. However, because the maxilla has more blood flow than other bone and the trabecular structure is a special environment, where various cells can move in the bloodstream at wide intervals, the results of this study are considered to be directly linked to clinical practice. Therefore, the extraction socket model was selected.

In the healing of human extraction sockets, the period of up to approximately 1 week is called the "clot stage", during which fibrin has a hemostatic effect and connective tissue proliferation occurs. The "granulation tissue stage" is at approximately 2 weeks, and as the epithelium heals, macrophages organize the blood clot. Around 3-4 weeks is the "callus stage", which is the time when granulation is replaced with new bone. After 5 weeks, the "bone remodeling stage" occurs and the bone tissue is strengthened by bone remodeling. The starting point of healing in this series is the presence of osteoclast progenitor cells, 
such as macrophages. Bone remodeling usually starts when osteoclasts appear, the signal coupling from osteoclasts promotes osteoblast bone formation and leads to neoplastic bone formation. Therefore, in this study, we focused on the activity of osteoclasts in the extraction socket as a method for evaluating bone formation.

In the experiment shown in Figure 1, RAW-D cell, an osteoclast precursor cell line, was used. This cell line was isolated from RAW264 cells in 2004 and has since been used in many basic studies to evaluate osteoclast behavior $[15,28,29]$. In these experiments, which showed the ability to differentiate into osteoclast-like cells in the $\mathrm{AB}$ and $\mathrm{CO}_{3} \mathrm{Ap}$ experimental groups, the number of multinucleated osteoclast-like cells increased comparably to AB in the presence of $\mathrm{CO}_{3} \mathrm{Ap}$ (Figure 1B). Furthermore, the thick protrusion shape and bearing three or more nuclei of the osteoclasts on the $\mathrm{CO}_{3} \mathrm{Ap}$ was a characteristic result. In other words, the control group supported osteoclast-like cells with an oval shape, and the cells on the experimental group were star-shaped and large (Figure 1C). Given the number and shape of the cells indicate the strength of the activity of osteoclasts [30], the osteoclastlike cells on the $\mathrm{CO}_{3} \mathrm{Ap}$ and autogenous bone showed high TRAP activity. Previous studies have reported that the rougher the implant body surface, the greater the number of multinuclear giant cells that appear. Therefore, the results in this experiment may be influenced by the composition and the surface roughness of the materials. Alternatively, $\mathrm{CO}_{3} \mathrm{Ap}$ releases large amounts of calcium and phosphate ions into solution [30-32], which may affect the activity of osteoclasts [30].

The process of bone replacement in the $\mathrm{CO}_{3} \mathrm{Ap}$ group over time was observed using the rat tooth extraction socket model. The observation period shown in Figure 2 was determined according to a previous study [33,34]. In a previous experiment in which $\mathrm{CO}_{3} \mathrm{Ap}$ was implanted in a rabbit femur, bone replacement was observed over 24 months using micro-CT images. However, it is difficult to compare the time of bone replacement because it is affected by the healing environment and wound size that can occur with different models. In rabbit and rat tibia fracture models, the rate of healing slows with body size [35-37]. The sagittal section through the central part of the second molar on the opposite side is shown in Figure 2C,D. For the bone thickness measurements shown in Figure 2E, the palatal root apex of the micro-CT image in Figure 2D was used as a landmark from which the vertical bone thickness was measured. The bone was significantly thicker in both the $\mathrm{AB}$ group and the $\mathrm{CO}_{3} \mathrm{Ap}$ group on day 5 in Figure 2E. However, because of the small size of the extraction socket in the present model, the experimental group of the bone replacement material caught up with the control group after approximately 14 days. If large animals, such as humans and dogs, were used as models, significant differences might be obtained. After 28 days of tooth extraction, only the $\mathrm{CO}_{3}$ Ap group showed a predominantly thicker bone than the control group. Over the long term, there may be a difference between $\mathrm{CO}_{3} \mathrm{Ap}$ and $\mathrm{AB}$ group.

The morphology of the same site was observed under HE staining (Figure 3A). An inflammatory reaction was not observed immediately after the bone substitute was transferred. Defective granulation tissue was not observed, while angiogenesis was clearly enhanced around $\mathrm{CO}_{3} \mathrm{Ap}$. Bone filling materials are foreign substances and may cause inflammation depending on their shape and size [32,35]. In addition, once infection occurs, the granulation tissue, which should be the starting point for healing, becomes poor granulation tissue and conversely suppresses healing [38]. It is considered that the soft tissue barrier is formed early by being filled with the bone filling materials [39,40]. In addition, because vascular endothelial cells can be easily determined from the HE-stained image, the enhancement of angiogenesis could be confirmed. Based on these results, osteoclast accumulation appeared around $\mathrm{CO}_{3} \mathrm{Ap}$, which may lead to early bone renewal. Furthermore, from the results of Azan staining in Figure 3B, collagen fibers (type I collagen, a main component of the organic part of bone) were abundant according to the staining concentration. The presence of collagen fibers suggests that the stained area is still immature [41]. Therefore, there was immature bone formation in the experimental group 
with strong staining of collagen fibers after 5 days. Collagen fiber was also observed in the control group, although not as prominently as in the experimental groups.

The osteoclast activity was observed (Figure 4) because osteoclasts attach to juvenile bone to initiate bone formation [42]. Cells with multiple nuclei and clearly larger than other cells were observed around $\mathrm{CO}_{3} \mathrm{Ap}$ (Figure 4A). The cells with these characteristics are likely to be osteoclasts.

Furthermore, cathepsin K-positive cells were observed around $\mathrm{CO}_{3} \mathrm{Ap}$ (Figure 4B). Because cathepsin $\mathrm{K}$ is a marker of osteoclast [24], the osteoclasts were activated around $\mathrm{CO}_{3} \mathrm{Ap}$ and consequently bone formation was promoted. In addition, because osteoclasts were observed around the bone filling material and throughout the extraction socket with TRAP staining, $\mathrm{CO}_{3} \mathrm{Ap}$ absorption occurs simultaneously in the entire sample. This is clearly different from the bone replacement of other materials that occur from the margins $[43,44]$, and the material may be quickly replaced by bone.

In aqueous solution, $\mathrm{CO}_{3} \mathrm{Ap}$ releases ions, such as carbonic acid, calcium, and phosphoric acid, which easily reduce the $\mathrm{pH}$ to create a suitable environment for osteoclasts. Furthermore, $\mathrm{CO}_{3} \mathrm{Ap}$ is stable at in vivo $\mathrm{pH}$ and dissolves well at extremely low $\mathrm{pH}$ [31]. Therefore, the reduced $\mathrm{pH}$ by osteoclasts elutes carbonate apatite and releases ions, leading to a cycle in which the $\mathrm{pH}$ is further reduced. Furthermore, as shown in Figure $1 \mathrm{C}, \mathrm{CO}_{3} \mathrm{Ap}$ is an environment in which osteoclast-like cells are likely to adhere.

Autogenous bone is an excellent material as a bone substitute; however, the amount of absorption is easily affected by the limitations of the filling amount and surrounding bone environment. Furthermore, the hardening is easily affected by the collection site and it is difficult to control the prognosis of treatment. Understanding the process by which $\mathrm{CO}_{3} \mathrm{Ap}$, an artificial material used as a bone substitute, is indispensable for controlling the prognosis. Therefore, $\mathrm{CO}_{3} \mathrm{Ap}$ is a bone substitute that potentially meets clinical needs more than autogenous bone.

\section{Conclusions}

In this study, the bone replacement process of $\mathrm{CO}_{3} \mathrm{Ap}$ in the extraction socket model was observed. Although $\mathrm{CO}_{3} \mathrm{Ap}$ is a synthetic material, the process of bone replacement by osteoclasts was similar to that of autogenous bone. By observing the process of bone replacement in more detail in the future, it may be possible to obtain a better understanding of the bone formation compared with autogenous bone.

Author Contributions: Conceptualization, Investigation, Methodology, and Writing-Original draft preparation, X.Z.; Investigation, Methodology, Writing-Reviewing, and Editing, I.A.; Formal analysis, Y.A.; Investigation, I.N.; Methodology, N.U.; Methodology, R.T.; Methodology, Y.E.; Methodology and Editing, J.-Q.Z.; Methodology, J.-Y.G.; Conceptualization, Project, K.K. All authors have read and agreed to the published version of the manuscript.

Funding: This work was supported by JSPS KAKENHI Grant Numbers JP 18K09662 (to I. A).

Institutional Review Board Statement: Our in vivo and in vitro study were approved by the guidelines established by the Laboratory Animal Care and Use Committee of Kyushu University (approval number: A25-240-0).

Informed Consent Statement: Not applicable.

Data Availability Statement: The data presented in this study are available on request from the corresponding author.

Acknowledgments: We thank Ashleigh Cooper, from Edanz Group (https:/ / en-author-services. edanzgroup.com/ac (accessed on 22 December 2020)) for editing a draft of this manuscript.

Conflicts of Interest: I.A. and K.K. belong to the Division of Advanced Dental Devices and Therapeutics, Faculty of Dental Science, Kyushu University. This division and Cytrans are endowed by GC Corporation, Tokyo, Japan. GC Corporation had no specific roles in the conceptualization, design, data collection, analysis, decision to publish, or preparation of the manuscript. All other authors declare they have no competing interests. 


\section{References}

1. Myeroff, C.; Archdeacon, M. Autogenous bone graft: Donor sites and techniques. J. Bone Joint Surg. 2011, 93, 2227-2236. [CrossRef] [PubMed]

2. Sakkas, A.; Wilde, F.; Heufelder, M.; Winter, K.; Schramm, A. Autogenous bone grafts in oral implantology-is it still a "gold standard"? A consecutive review of 279 patients with 456 clinical procedures. Int. J. Implant Dent. 2017, 3, 23. [CrossRef]

3. Hallman, M.; Sennerby, L.; Lundgren, S. A clinical and histologic evaluation of implant integration in the posterior maxilla after sinus floor augmentation with autogenous bone, bovine hydroxyapatite, or a 20:80 mixture. Int. J. Oral Maxillofac. Implant. 2002, 17, 635-643.

4. Sargolzaie, N.; Rafiee, M.; Salari, S.H.; Zare, M.R.; Keshavarz, H. Comparison of the effect of hemihydrate calcium sulfate granules and Cerabone on dental socket preservation: An animal experiment. J. Dent. Res. Dent. Clin. Dent. Prospect. 2018, 12, 238-244. [CrossRef]

5. Velard, F.; Schlaubitz, S.; Fricain, J.C.; Guillaume, C.; Laurent-Maquin, D.; Moller-Siegert, J.; Vidal, L.; Jallot, E.; Sayen, S.; Raissle, O.; et al. In vitro and in vivo evaluation of the inflammatory potential of various nanoporous hydroxyapatite biomaterials. Nanomedicine 2015, 10, 785-802. [CrossRef]

6. Goto, T.; Kojima, T.; Ijima, T.; Yokokura, S.; Kawano, H.; Yamamoto, A.; Matsuda, K. Resorption of synthetic porous hydroxyapatite and replacement by newly formed bone. J. Orthop. Sci. 2001, 6, 444-447. [CrossRef]

7. Fujisawa, K.; Akita, K.; Fukuda, N.; Kamada, K.; Kudoh, T.; Ohe, G.; Mano, T.; Tsuru, K.; Ishikawa, K.; Miyamoto, Y. Compositional and histological comparison of carbonate apatite fabricated by dissolution-precipitation reaction and Bio-Oss((R)). J. Mater. Sci. Mater. Med. 2018, 29, 121. [CrossRef] [PubMed]

8. Kudoh, K.; Fukuda, N.; Kasugai, S.; Tachikawa, N.; Koyano, K.; Matsushita, Y.; Ogino, Y.; Ishikawa, K.; Miyamoto, Y. Maxillary Sinus Floor Augmentation Using Low-Crystalline Carbonate Apatite Granules With Simultaneous Implant Installation: First-inHuman Clinical Trial. J. Oral. Maxillofac. Surg. 2019, 77, 985.e1-985.e11. [CrossRef]

9. Charles, J.F.; Aliprantis, A.O. Osteoclasts: More than 'bone eaters'. Trends Mol. Med. 2014, 20, 449-454. [CrossRef] [PubMed]

10. Lin, X.; Matsuya, S.; Nakagawa, M.; Terada, Y.; Ishikawa, K. Effect of molding pressure on fabrication of low-crystalline calcite block. J. Mater. Sci. Mater. Med. 2008, 19, 479-484. [CrossRef]

11. Wakae, H.; Takeuchi, A.; Udoh, K.; Matsuya, S.; Munar, M.L.; LeGeros, R.Z.; Nakasima, A.; Ishikawa, K. Fabrication of macroporous carbonate apatite foam by hydrothermal conversion of alpha-tricalcium phosphate in carbonate solutions. J. Biomed. Mater. Res. A 2008, 87, 957-963. [CrossRef]

12. Ishikawa, K. Bone Substitute Fabrication Based on Dissolution-Precipitation Reactions. Materials 2010, 3, 1138-1154. [CrossRef]

13. Ishikawa, K.; Matsuya, S.; Lin, X.; Lei, Z.; Yuasa, T.; Miyamoto, Y. Fabrication of low crystalline B-type carbonate apatite block from low crystalline calcite block. J. Ceram. Soc. Jpn. 2010, 118, 341-344. [CrossRef]

14. Kukita, T.; Wada, N.; Kukita, A.; Kakimoto, T.; Sandra, F.; Toh, K.; Nagata, K.; Iijima, T.; Horiuchi, M.; Matsusaki, H.; et al. RANKL-induced DC-STAMP is essential for osteoclastogenesis. J. Exp. Med. 2004, 200, 941-946. [CrossRef] [PubMed]

15. Watanabe, T.; Kukita, T.; Kukita, A.; Wada, N.; Toh, K.; Nagata, K.; Nomiyama, H.; Iijima, T. Direct stimulation of osteoclastogenesis by MIP-1 alpha: Evidence obtained from studies using RAW264 cell clone highly responsive to RANKL. J. Endocrinol. 2004, 180, 193-201. [CrossRef]

16. Kukita, T.; Takahashi, A.; Zhang, J.Q.; Kukita, A. Membrane nanotube formation in osteoclastogenesis. Methods Mol. Biol. 2015, 1313, 193-202. [PubMed]

17. Takemura, Y.; Moriyama, Y.; Ayukawa, Y.; Kurata, K.; Rakhmatia, Y.D.; Koyano, K. Mechanical loading induced osteocyte apoptosis and connexin 43 expression in three-dimensional cell culture and dental implant model. J. Biomed. Mater. Res. A 2019, 107, 815-827. [CrossRef] [PubMed]

18. Narimatsu, I.; Atsuta, I.; Ayukawa, Y.; Oshiro, W.; Yasunami, N.; Furuhashi, A.; Koyano, K. Epithelial and Connective Tissue Sealing around Titanium Implants with Various Typical Surface Finishes. ACS Biomater. Sci. Eng. 2019, 5, 4976-4984. [CrossRef]

19. The ARRIVE Guidelines: Animal Research: Reporting of In Vivo Experiments. Available online: https://www.nc.3rs.org.uk/ sites/default/files/documents/Guidelines/NC3Rs\%20ARRIVE\%20Guidelines\%202013.pdf (accessed on 23 July 2019 ).

20. Imai, M.; Ayukawa, Y.; Yasunami, N.; Furuhashi, A.; Takemura, Y.; Adachi, N.; Hu, J.; Zhou, X.; Moriyama, Y.; Atsuta, I.; et al. Effect of a Single Injection of Benidipine-Impregnated Biodegradable Microcarriers on Bone and Gingival Healing at the Tooth Extraction Socket. Adv. Wound Care 2019, 8, 108-117. [CrossRef]

21. Adachi, N.; Ayukawa, Y.; Yasunami, N.; Furuhashi, A.; Imai, M.; Sanda, K.; Atsuta, I.; Koyano, K. Preventive effect of fluvastatin on the development of medication-related osteonecrosis of the jaw. Sci. Rep. 2020, 10, 5620. [CrossRef]

22. Atsuta, I.; Ayukawa, Y.; Furuhashi, A.; Narimatsu, I.; Kondo, R.; Oshiro, W.; Koyano, K. Epithelial sealing effectiveness against titanium or zirconia implants surface. J. Biomed. Mater. Res. A 2019, 107, 1379-1385. [CrossRef]

23. Takamori, Y.; Atsuta, I.; Nakamura, H.; Sawase, T.; Koyano, K.; Hara, Y. Histopathological comparison of the onset of periimplantitis and periodontitis in rats. Clin. Oral Implant. Res. 2017, 28, 163-170. [CrossRef]

24. Szewczyk, K.A.; Fuller, K.; Chambers, T.J. Distinctive subdomains in the resorbing surface of osteoclasts. PLoS ONE 2013, 8, e60285. [CrossRef]

25. Kitami, S.; Tanaka, H.; Kawato, T.; Tanabe, N.; Katono-Tani, T.; Zhang, F.; Suzuki, N.; Yonehara, Y.; Maeno, M. IL-17A suppresses the expression of bone resorption-related proteinases and osteoclast differentiation via IL-17RA or IL-17RC receptors in RAW264.7 cells. Biochimie 2010, 92, 398-404. [CrossRef] 
26. Pietrokovski, J.; Massler, M. Ridge remodeling after tooth extraction in rats. J. Dent. Res. 1967, 46, 222-231. [CrossRef] [PubMed]

27. Ferreira, M.M.; Brito, A.F.; Marques, C.F.; Freitas, L.F.; Carrilho, E.; Abrantes, A.M.; Pires, A.S.; Aguiar, M.J.; Carvalho, L.; Botelho, M.F.; et al. Can the regenerative potential of an alkali-free bioactive glass composition be enhanced when mixed with resorbable $\beta$-TCP? Ceram. Int. 2018, 44, 5025-5031. [CrossRef]

28. Takahashi, A.; Kukita, A.; Li, Y.J.; Zhang, J.Q.; Nomiyama, H.; Yamaza, T.; Ayukawa, Y.; Koyano, K.; Kukita, T. Tunneling nanotube formation is essential for the regulation of osteoclastogenesis. J. Cell. Biochem. 2013, 114, 1238-1247. [CrossRef] [PubMed]

29. Badawy, T.; Kyumoto-Nakamura, Y.; Uehara, N.; Zhang, J.Q.; Sonoda, S.; Hiura, H.; Yamaza, T.; Kukita, A.; Kukita, T. Osteoblast lineage-specific cell-surface antigen (A7) regulates osteoclast recruitment and calcification during bone remodeling. Lab. Investig. 2019, 99, 866-884. [CrossRef]

30. Doi, Y.; Iwanaga, H.; Shibutani, T.; Moriwaki, Y.; Iwayama, Y. Osteoclastic responses to various calcium phosphates in cell cultures. J. Biomed. Mater. Res. 1999, 47, 424-433. [CrossRef]

31. Ishikawa, K. Carbonate apatite bone replacement: Learn from the bone. J. Ceram. Soc. Jpn. 2019, 127, 595-601. [CrossRef]

32. Hesaraki, S.; Nazarian, H.; Pourbaghi-Masouleh, M.; Borhan, S. Comparative study of mesenchymal stem cells osteogenic differentiation on low-temperature biomineralized nanocrystalline carbonated hydroxyapatite and sintered hydroxyapatite. J. Biomed. Mater. Res. B Appl. Biomater. 2014, 102, 108-118. [CrossRef]

33. Hadaya, D.; Soundia, A.; Gkouveris, I.; Dry, S.M.; Aghaloo, T.L.; Tetradis, S. Development of Medication-Related Osteonecrosis of the Jaw After Extraction of Teeth with Experimental Periapical Disease. J. Oral Maxillofac. Surg. 2019, 77, 71-86. [CrossRef]

34. Soundia, A.; Hadaya, D.; Esfandi, N.; Gkouveris, I.; Christensen, R.; Dry, S.M.; Bezouglaia, O.; Pirih, F.; Nikitakis, N.; Aghaloo, T.; et al. Zoledronate Impairs Socket Healing after Extraction of Teeth with Experimental Periodontitis. J. Dent. Res. 2018, 97, 312-320. [CrossRef]

35. Shanbhag, A.S.; Jacobs, J.J.; Black, J.; Galante, J.O.; Glant, T.T. Macrophage/particle interactions: Effect of size, composition and surface area. J. Biomed. Mater. Res. 1994, 28, 81-90. [CrossRef]

36. Zhukauskas, R.; Dodds, R.A.; Hartill, C.; Arola, T.; Cobb, R.R.; Fox, C. Histological and radiographic evaluations of demineralized bone matrix and coralline hydroxyapatite in the rabbit tibia. J. Biomater. Appl. 2010, 24, 639-656. [CrossRef]

37. Liu, Y.; Wang, D.; Wu, X.; Zhou, J. Ischemia Injury: A New Method Accelerates Bone Healing in a Rat Tibia Fracture Model. Biomed. Res. Int. 2019, 2019, 6592464. [CrossRef]

38. Crespi, R.; Cappare, P.; Gastaldi, G.; Gherlone, E. Reactive Soft Tissue Preservation in Large Bone Defects After Tooth Extractions: A Cone Beam Study. Int. J. Oral. Maxillofac. Implant. 2016, 31, 179-185. [CrossRef]

39. Laurito, D.; Cugnetto, R.; Lollobrigida, M.; Guerra, F.; Vestri, A.; Gianno, F.; Bosco, S.; Lamazza, L.; De Biase, A. Socket Presevation with d-PTFE Membrane: Histologic Analysis of the Newly Formed Matrix at Membrane Removal. Int. J. Periodontics Restor. Dent. 2016, 36, 877-883. [CrossRef]

40. Laurito, D.; Lollobrigida, M.; Gianno, F.; Bosco, S.; Lamazza, L.; De Biase, A. Alveolar Ridge Preservation with nc-HA and d-PTFE Membrane: A Clinical, Histologic, and Histomorphometric Study. Int. J. Periodontics Restor. Dent. 2017, 37, 283-290. [CrossRef]

41. Sato, N.; Handa, K.; Venkataiah, V.S.; Hasegawa, T.; Njuguna, M.M.; Yahata, Y.; Saito, M. Comparison of the vertical bone defect healing abilities of carbonate apatite, beta-tricalcium phosphate, hydroxyapatite and bovine-derived heterogeneous bone. Dent. Mater. J. 2020, 39, 309-318. [CrossRef] [PubMed]

42. Karsdal, M.A.; Martin, T.J.; Bollerslev, J.; Christiansen, C.; Henriksen, K. Are nonresorbing osteoclasts sources of bone anabolic activity? J. Bone Miner. Res. 2007, 22, 487-494. [CrossRef]

43. Lim, H.C.; Song, K.H.; You, H.; Lee, J.S.; Jung, U.W.; Kim, S.Y.; Choi, S.H. Effectiveness of biphasic calcium phosphate block bone substitutes processed using a modified extrusion method in rabbit calvarial defects. J. Periodontal Implant. Sci. 2015, 45, 46-55. [CrossRef]

44. Zeng, D.; Zhang, X.; Wang, X.; Cao, L.; Zheng, A.; Du, J.; Li, Y.; Huang, Q.; Jiang, X. Fabrication of large-pore mesoporous Ca-Si-based bioceramics for bone regeneration. Int. J. Nanomed. 2017, 12, 8277-8287. [CrossRef] 